\title{
Protection Against Ischemia-Induced Ventricular Arrhythmias and Myocardial Dysfunction Conferred by Preconditioning in the Rat Heart: Involvement of Mitochondrial $K_{\mathrm{ATP}}$ Channels and Reactive Oxygen Species
}

\author{
J. MATEJÍKOVÁ, J. KUCHARSKÁ ${ }^{1}$, M. PINTÉROVÁ ${ }^{2}$, D. PANCZA, T. RAVINGEROVÁ \\ Institute for Heart Research, Slovak Academy of Sciences, Centre of Excellence for Cardiovascular \\ Research of the SAS, ${ }^{1}$ Pharmacobiochemical Laboratory, Faculty of Medicine, Comenius \\ University, Bratislava, Slovak Republic, and ${ }^{2}$ Institute of Physiology, Academy of Sciences of the \\ Czech Republic, Centre of Experimental Cardiovascular Research, Prague, Czech Republic
}

Received May 29, 2007

Accepted November 5, 2007

On-line January 17, 2008

\begin{abstract}
Summary
Ischemic preconditioning (I-PC) induced by brief episodes of ischemia and reperfusion (I/R) protects the heart against sustained I/R. Although activation of mitochondrial $K_{\text {ATP }}$ channels (mitoK $\mathrm{ATP}_{\text {) }}$ interacting with reactive oxygen species (ROS) has been proposed as a key event in this process, their role in the antiarrhythmic effect is not clear. This study was designed: 1 ) to investigate the involvement of mito $K_{\text {ATP }}$ opening in the effect of I-PC (1 cycle of I/R, 5 min each) on ventricular arrhythmias during test ischemia ( $\mathrm{TI}, 30$-min LAD coronary artery occlusion) in Langendorff-perfused rat hearts and subsequent postischemic contractile dysfunction, and 2) to characterize potential mechanisms of protection conferred by I-PC and pharmacological PC induced by mito $K_{\text {ATP }}$ opener diazoxide (DZX), with particular regards to the modulation of ROS generation. Lipid peroxidation (an indicator of increased ROS production) was determined by measurement of myocardial concentration of conjugated dienes (CD) and thiobarbituric acid reactive substances (TBARS) in nonischemic controls, non-preconditioned and preconditioned hearts exposed to TI, I-PC alone, as well as after pretreatment with DZX, mito $\mathrm{K}_{\text {ATP }}$ blocker 5-hydroxydecanoate (5-HD) and antioxidant $\mathrm{N}$-acetylcysteine (NAC). Total number of ventricular premature beats (VPB) that occurred in the control hearts $(518 \pm 71)$ was significantly $(P<0.05)$ reduced by I-PC $(195 \pm 40)$, NAC $(290 \pm 56)$ and DZX (168 \pm 22$)$. I-PC and NAC suppressed an increase in $C D$ and TBARS caused by ischemia indicating lower production of ROS. On the other hand, I-PC and DZX themselves moderately enhanced ROS generation, prior to TI. Bracketing of I-PC with 5-HD suppressed both, ROS production during PC and
\end{abstract}

its cardioprotective effect. In conclusion, potential mechanisms of protection conferred by mito $\mathrm{K}_{\mathrm{ATP}}$ opening in the rat heart might involve a temporal increase in ROS production in the preconditioning phase triggering changes in the pro/antioxidant balance in the myocardium and attenuating ROS production during subsequent prolonged ischemia.

\section{Key words}

Myocardial ischemia $\bullet$ Arrhythmias $\bullet$ Preconditioning $\bullet$ mito $K_{\text {ATP }}$ channels • Rat heart

\section{Corresponding author}

T. Ravingerová, Institute for Heart Research, Slovak Academy of Sciences, POB 104, Dúbravská cesta 9, 84005 Bratislava, Slovak Republic. Fax +421 254776637. E-mail usrdravi@savba.sk

\section{Introduction}

Severe ventricular arrhythmias represent a major challenge for therapeutic intervention due to complexity of pathophysiological mechanisms initiating arrhythmias in ischemic heart disease (Bril 1996), and the development of a new approach to management of arrhythmias is urgently needed. Imbalance between the formation of reactive oxygen species (ROS) and the availability of endogenous antioxidants caused by ischemia and reperfusion ( $\mathrm{I} / \mathrm{R})$ plays an important role in the genesis of myocardial injury (McCord 1985, Kloner 
et al. 1989, Dhalla et al. 2000) and might lead to occurrence of malignant ischemia- and reperfusioninduced arrhythmias (Yang et al. 1995, Ravingerová et al. 1999). Negative effect of an oxidative load has been further supported by the ability of exogenously administrated free radical scavengers to improve functional recovery of the postischemic-reperfused heart (Downey et al. 1991, Tang and Tang 1991, Qiu et al. 1992).

Ischemic preconditioning (I-PC) is a concept of cardioprotection against lethal ischemia based on the exploitation of endogenous protective mechanisms activated by prior periods of brief ischemia (Murry 1986, Ravingerová et al. 2002, Das and Sarkar 2005). Recent studies demonstrated that preconditioning (PC) is involved in the attenuation of altered cellular redox state and deleterious effects of ROS (Das and Maulik 2003). Although we do not yet understand completely molecular mechanisms responsible for cardioprotection afforded by $\mathrm{PC}$, compelling evidence suggests that ATP-sensitive $\mathrm{K}^{+}$ $\left(\mathrm{K}_{\mathrm{ATP}}\right)$ channels localized in different cell compartments are central players in this process (Gross and Fryer 1999, Végh and Parratt 2002, Das and Sarkar 2005). Opening of sarcolemmal $\mathrm{K}_{\mathrm{ATP}}$ channels has been initially suggested as an end-effector mechanism in the preconditioning cascade since their blockade with $\mathrm{K}_{\mathrm{ATP}}$ blocker glibenclamide abolished I-PC in dogs (Gross and Auchampach 1992), strengthened by the observations that $\mathrm{K}_{\text {ATP }}$ openers could mimic the I-PC-induced protection (Grover et al. 1994, Gross and Fryer 1999). However, $\mathrm{K}_{\mathrm{ATP}}$ modulations may exert both, anti- and proarrhythmic effects (Tosaki et al. 1992). Moreover, it has also been revealed that cardioprotection occurs independently from the changes in action potential duration, which is the main determinant of arrhythmogenesis and a target of sarcolemmal $\mathrm{K}_{\text {ATP }}$ openers (Hamada et al. 1998). In line, our previous study demonstrated that $\mathrm{K}_{\mathrm{ATP}}$ blockade with glibenclamide did not reverse antiarrhythmic protection conferred by I-PC (Ravingerová et al. 2002). Furthermore, a selective inhibitor of $\mathrm{K}_{\mathrm{ATP}}$ channels localized in mitochondria (mito $\mathrm{K}_{\text {ATP }}$ ) 5-hydroxydecanoate (5-HD) abolished protection against contractile dysfunction in guinea pig papillary muscle conferred by hypoxic PC (Ravingerová et al. 1998) and cardioprotection afforded by I-PC (Sato et al. 2000) including anti-infarct protection in rabbits and rats, without affecting ischemia-induced shortening of action potential duration (Munch-Ellingsen et al. 2000). Finally, Garlid et al. (2003) proposed that mito
$\mathrm{K}_{\mathrm{ATP}}$ channel is 2000 -fold more sensitive than the sarcolemmal one to $\mathrm{K}_{\mathrm{ATP}}$ opener diazoxide, which has been shown to mimic the I-PC-induced cardioprotection, and that it is the most likely end-effector involved with I-PC. On the other hand, mito $\mathrm{K}_{\mathrm{ATP}}$ opening could play not only the end-effector role in the preconditioning cascade, but it can also trigger this chain of events and act as an upstream mechanism of protein kinases activation mediated by an increased production of ROS and nitric oxide (Yue et al. 2002).

Although application of diazoxide has been shown to exert cardioprotective effects (Asemu et al. 1999), the mechanism of antiarrhythmic protection induced by mito $\mathrm{K}_{\mathrm{ATP}}$ opening remains less elucidated. In the present study, we tested the hypothesis that I-PC elicits its antiarrhythmic effects through the opening of mito $\mathrm{K}_{\mathrm{ATP}}$ channels and that pharmacologically induced PC by exogenously applied mito $K_{\text {ATP }}$ activator can afford similarly effective antiarrhythmic protection followed by an improvement of postischemic contractile recovery in isolated rat heart. Our further goal was to elucidate the mechanisms of cardioprotective effect of mito $\mathrm{K}_{\mathrm{ATP}}$ opening with particular regards to the modulation of ROS production in the preconditioned myocardium.

\section{Materials and Methods}

\section{Animals}

Male Wistar rats (250-300 g body weight), fed a standard diet and tap water ad libitum, were employed. All studies were performed in accordance with the Guide for the Care and Use of Laboratory Animals published by US National Institutes of Health (NIH publication No 8523, revised 1996) and approved by the Animal Care and Use Committee of the Slovak Republic.

\section{Perfusion technique}

Rats were anesthetized (sodium pentobarbitone, $60 \mathrm{mg} / \mathrm{kg}$, i.p.) and given heparin (500 IU, i.p.). Hearts were rapidly excised, placed in ice-cold perfusion buffer, cannulated via the aorta and perfused in the Langendorff mode at a constant perfusion pressure of $70 \mathrm{~mm} \mathrm{Hg}$ and at $37{ }^{\circ} \mathrm{C}$. The perfusion solution was a modified KrebsHenseleit buffer gassed with $95 \% \mathrm{O}_{2}$ and $5 \% \mathrm{CO}_{2}$ (pH 7.4) containing (in $\mathrm{mM}$ ): $\mathrm{NaCl} 118.0, \mathrm{KCl} 3.0$, $\mathrm{MgSO}_{4}$ 1.2, $\mathrm{NaHCO}_{3}$ 25.0, $\mathrm{NaH}_{2} \mathrm{PO}_{4}$ 1.18, $\mathrm{CaCl}_{2}$ 2.5, glucose 5.5. Reduced potassium and enhanced calcium concentrations in the above buffer were used to promote 
arrhythmogenesis during ischemia. Solution was filtered through a $5 \mu \mathrm{m}$ porosity filter (Millipore) to remove contaminants. An epicardial electrogram was registered by means of two stainless steel electrodes attached to the apex of the heart and the aortic cannula.

Left ventricular pressure was measured by means of a non-elastic water-filled balloon inserted into the left ventricle via the left atrium (adjusted to obtain end-diastolic pressure of 5-7 $\mathrm{mm} \mathrm{Hg}$ ) and connected to a pressure transducer (MLP844 Physiological Pressure Transducer, ADInstruments). Left ventricular developed pressure (LVDP, systolic minus diastolic pressure), maximal rates of pressure development and fall, $+\mathrm{dP} / \mathrm{dt}_{\max }$ and $-\mathrm{dP} / \mathrm{dt}_{\max }$, as the indexes of contraction and relaxation, as well as the heart rate (derived from electrogram) and coronary flow were monitored during stabilization, pre-ischemia period (for the evaluation of the effect of pharmacological interventions on hemodynamic parameters), and were continuously recorded until the end of experiment. Its recovery after ischemia/reperfusion was expressed as percentage of preischemic baseline values. Heart function and arrhythmias were analyzed using PowerLab/8SP Chart 5 software (ADInstruments). The hearts were allowed to stabilize $(15 \mathrm{~min})$ before further interventions.

\section{Induction of ischemia}

At the onset of experiment a ligature was placed loosely around the left anterior descending (LAD) coronary artery close to its origin. Both ends of the suture were threaded through a traction-type plastic occluder. Regional ischemia (LAD artery occlusion) was induced by traction of the suture against the plastic cannula and clamping the suture. After 30-min ischemia, the ligature was released to permit reperfusion. A fall in coronary flow by approximately $40 \%$ at the onset of ischemia and its increase upon reperfusion verified the efficacy of LAD occlusion. For the evaluation of postischemic functional recovery, in the additional subset of experiments the hearts underwent 25-min global ischemia (induced by closing of the aortic inflow) followed by 40-min reperfusion.

\section{Quantification of arrhythmias}

Susceptibility to ischemia-induced ventricular arrhythmias was analyzed from the electrocardiogram recording following the guidelines for the study of ischemia and reperfusion arrhythmias known as The Lambeth Conventions (Walker et al. 1988). We focused on the measurement of the total number of ventricular premature beats (VPB) over the whole period of ischemia, as well as on the incidence and duration of ventricular tachycardia (VT), which was defined as a run of four or more consecutive ectopic beats.

\section{Perfusion protocols}

\section{1) Control test ischemia (TI)}

After 15 min equilibration and additional $15 \mathrm{~min}$ perfusion, the hearts were subjected either to regional ischemia (occlusion of LAD) lasting $30 \mathrm{~min}$ followed by 10-min reperfusion or to 25 -min global ischemia and 40 -min reperfusion ( $\mathrm{n}=8$ per group).

\section{2) Perfusion with antioxidant $\mathrm{N}$-acetylcysteine $(\mathrm{NAC}+\mathrm{I})$}

After equilibration, NAC (4 mmol/l $)$ was administered for $15 \mathrm{~min}$, prior to TI induced by regional $(n=9)$ or global $(n=6)$ ischemia/reperfusion.

\section{3) Ischemic preconditioning (I-PC+I)}

After equilibration, the hearts were subjected to one cycle of ischemic preconditioning consisting of 5-min ischemia and 5-min reperfusion, prior to TI induced by regional $(\mathrm{n}=9)$ or global $(\mathrm{n}=6)$ ischemia/reperfusion.

\section{4) Pharmacological preconditioning (DZX+I)}

Selective mito $\mathrm{K}_{\mathrm{ATP}}$ opener diazoxide (DZX, $50 \mu \mathrm{M}$ ) dissolved in dimethyl sulfoxide (DMSO) was used to mimic I-PC and was administered $15 \mathrm{~min}$ prior to TI induced by regional $(\mathrm{n}=8)$ or global $(\mathrm{n}=7)$ ischemia/reperfusion.

5) Perfusion with selective inhibitor of mito $K_{\text {ATP }}$ channels 5-HD in non-preconditioned hearts (5-HD+I)

5-HD $(200 \mu \mathrm{M})$ was administered $15 \mathrm{~min}$ prior to TI induced by regional $(\mathrm{n}=6)$ or global $(\mathrm{n}=8)$ ischemia/reperfusion.

6) Perfusion with selective inhibitor of mito $K_{\text {ATP }}$ channels 5-HD in preconditioned hearts (I-PC $+5-\mathrm{HD}+\mathrm{I})$

5 -HD $(200 \mu \mathrm{M})$ was administered throughout the preconditioning protocol $15 \mathrm{~min}$ prior to TI induced by regional $(\mathrm{n}=14)$ or global $(\mathrm{n}=6)$ ischemia/reperfusion.

\section{Measurement of lipid peroxidation}

In parallel subsets of experiments, concentration of conjugated dienes $(\mathrm{CD}$, a marker of lipid peroxidation 
due to increased ROS production) was measured in lipid extracts of the left ventricular tissue according to Kogure et al. (1982). Briefly, after chloroform evaporation under the inert atmosphere of nitrogen and after the addition of $3 \mathrm{ml}$ cyclohexane, concentration of CD was determined spectrophotometrically ( $\lambda 223 \mathrm{~nm}, \varepsilon 290001 . \mathrm{mol}^{-1} . \mathrm{cm}^{-1}$, SECOMAN). In addition, lipid peroxidation was also evaluated by measuring the formation of thiobarbituric acid reactants (TBARS) according to Ohkawa et al. (1979). The sampling for TBARS and CD ( $n=6-8$ in each group) was performed immediately after equilibration of the hearts (control samples, C) and following TI in the non-preconditioned (TI) and preconditioned hearts $(\mathrm{I}-\mathrm{PC}+\mathrm{I})$. In addition, concentration of $\mathrm{CD}$ was also measured immediately after I-PC or after 15-min pretreatment with DZX, as well as after I-PC and simultaneous pretreatment with 5-HD (I-PC+5-HD) or NAC (I-PC+NAC).

\section{Chemicals}

Diazoxide was obtained from Alexis Biochemicals. 5-hydroxydecanoate and N-acetylcysteine were purchased from Sigma Chemical Co. (St. Louis, MO, USA). Diazoxide was dissolved in dimethyl sulfoxide (Lachema, Czech Republic) before being added into experimental solutions. The final concentration of dimethyl sulfoxide was less than $0.01 \%$. All other chemicals were from Centralchem (Bratislava, Slovak Republic).

\section{Statistical evaluation}

The data were expressed as means \pm S.E.M. One-way ANOVA and subsequent Student-NewmanKeuls test were used for comparison of differences in variables with normal distribution between the groups. Variables with non-parametric distribution were compared by using Mann-Whitney (differences in the numbers of VPB, the numbers of episodes of VT and its duration) or Fisher's exact test (incidence of VT). Differences were considered as significant at $\mathrm{P}<0.05$.

\section{Results}

\section{Characteristics of isolated hearts}

The values of heart rate, LVDP, LVEDP, $+\mathrm{dP} / \mathrm{dt}_{\max },-\mathrm{dP} / \mathrm{dt}_{\max }$ and coronary flow in the control nonpreconditioned and preconditioned groups, as well as in drug-treated control and preconditioned hearts are summarized in Table 1. There were no significant

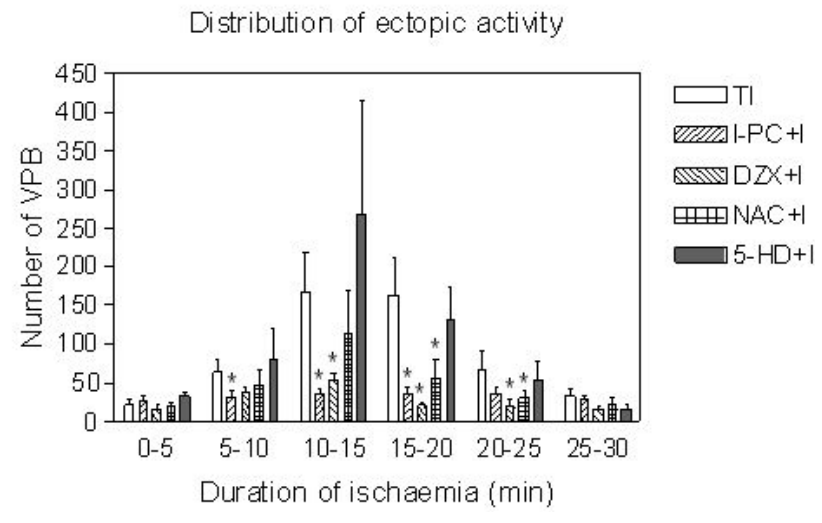

Fig. 1. Temporal pattern of the distribution of ectopic activity in 5-min intervals during 30-min ischemia in the rat heart. VPB ventricular premature beats. Values are means \pm S.E.M. of 6-9 hearts per group. ${ }^{*} \mathrm{P}<0.05$ vs. control ischemic group (TI).

differences in the values of these parameters between the groups at baseline and before TI.

Effect of $N A C$, ischemic preconditioning, diazoxide and 5-HD on susceptibility to ventricular arrhythmias

Occlusion of LAD coronary artery caused an immediate fall in coronary flow that was similar in all experimental groups. Myocardial ischemia resulted in a high ectopic activity in the control non-preconditioned group with a characteristic bell-shaped pattern of its temporal distribution with maximum between 10 and 20 min of ischemia (Fig. 1). VT was the most severe form of arrhythmia that occurred in all hearts. Marked attenuation of ectopic activity was observed in the preconditioned hearts (both, I-PC and pharmacologically induced PC), while pretreatment with 5-HD had no effect on the incidence of arrhythmias (Figs 1 and 3).

Administration of NAC significantly reduced a total number of VPB to $290 \pm 56$ from $518 \pm 71$ in the nontreated control hearts, decreased the mean number of the episodes of VT from $12.1 \pm 2.4$ to $5.3 \pm 1.8$ and shortened total duration of VT $(18.3 \pm 4.7 \mathrm{~s}$ vs. $43.6 \pm 8.6 \mathrm{~s}$ in the controls, $\mathrm{P}<0.05$, Fig. 2).

I-PC significantly suppressed the total number of VPB to $194.6 \pm 39.6(\mathrm{P}<0.05$, Fig. $2 \mathrm{~A})$. The number of episodes of VT (Fig. 2B) and its total duration (Fig. 2C) were also significantly reduced to $0.2 \pm 0.1$ and $0.7 \pm 0.3 \mathrm{~s}$, respectively, as compared with these parameters in nonpreconditioned controls $(\mathrm{P}<0.05)$.

An antiarrhythmic protection similar to that induced by I-PC was achieved by pharmacologically induced PC following application of diazoxide. Thus, there were only few VPB $(167.8 \pm 21.9$, Fig. $2 A)$ and 


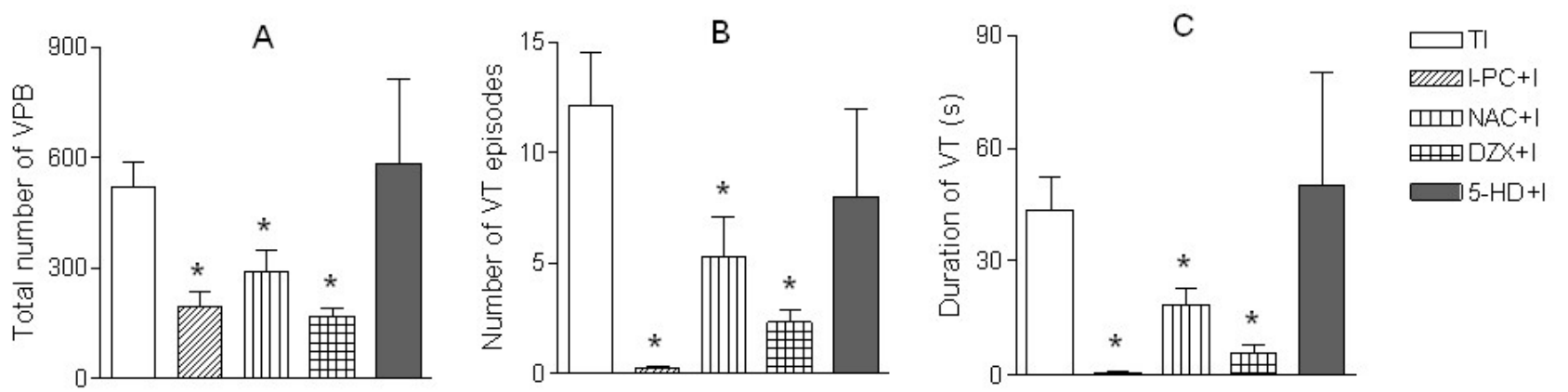

Fig. 2. Effects of $I-P C, K_{A T P}$ channels modulations and NAC on ischemia-induced ventricular arrhythmias in the rat heart. A: Number of ventricular premature beats. B: Number of episodes of VT. C: Duration of VT. VPB - ventricular premature beats, VT - ventricular tachycardia. Values are means \pm S.E.M. of 6-9 hearts per group. $* \mathrm{P}<0.05$ vs. control ischemic group (TI).

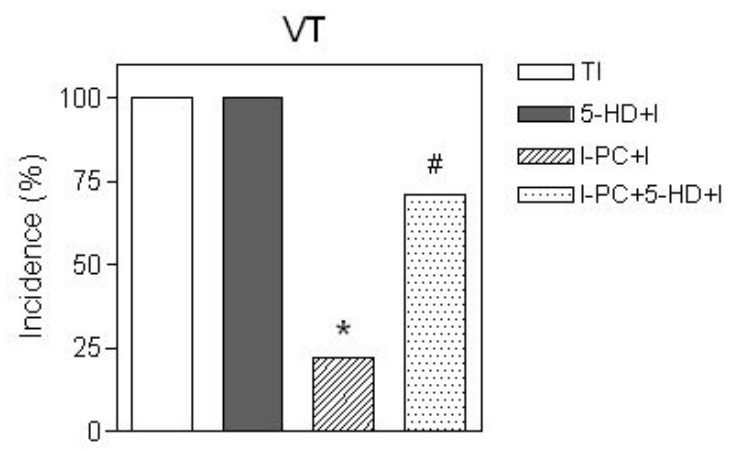

Fig. 3. Effect of $K_{A T P}$ inhibition on the incidence of ventricular tachycardia (VT) in the non-preconditioned and preconditioned rat hearts subjected to test ischemia (TI). Values are expressed as $\%$ of incidence, $n=6-14$ in each group. $* P<0.05$ vs. control

episodes of VT in the DZX-treated hearts $(2.3 \pm 0.6$, Fig. 2B). Total duration of VT was also significantly reduced in these hearts as compared with the controls $(5.3 \pm 2.2 \mathrm{~s}$, $\mathrm{P}<0.05$, Fig. 2C). This effect of I-PC and DZX was maximal between 5 and 25 min of ischemia (Fig. 1).

Although bracketing of preconditioning with 5-HD did not significantly increase the total number of VPB (not shown), blockade of mito $\mathrm{K}_{\text {ATP }}$ channels exacerbated arrhythmias and partially attenuated the effect of I-PC documented by an increased incidence of VT in these hearts (71\%) as compared with its incidence in the non-treated preconditioned hearts $(22 \%, \mathrm{P}<0.05)$ and $100 \%$ in both non-treated and 5-HD-treated ischemic controls (Fig. 3).

\section{Postischemic recovery of contractile function}

Pretreatment with NAC significantly improved recovery of LVDP after TI as compared with non-treated control hearts ( $50 \pm 6$ and $29 \pm 3 \%$ of preischemic values, respectively, $\mathrm{P}<0.05$, Table 2). Both, I-PC and DZX also markedly attenuated postischemic contractile dysfunction
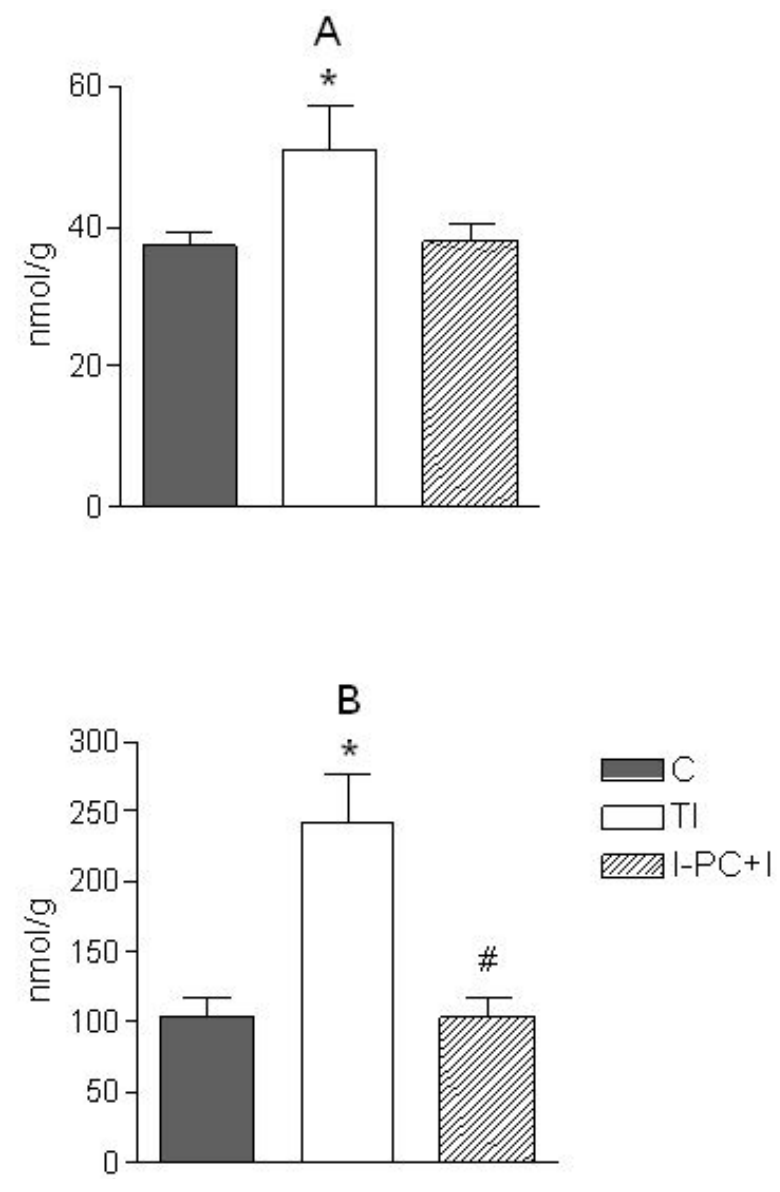

Fig. 4. Concentration of TBARS (A) and conjugated dienes (B) in the rat myocardium subjected to test ischemia (TI): effect of IPC. C- non-ischemic controls. Values are means \pm S.E.M, $n=6-8$ in each group. ${ }^{*} \mathrm{P}<0.05$ vs. $\mathrm{C},{ }^{*} \mathrm{P}<0.05$ vs. TI.

and increased LVDP recovery to $68 \pm 5$ and $70 \pm 5 \%$, respectively $(\mathrm{P}<0.05$ vs. controls). Pretreatment with 5-HD did not affect LVDP recovery in nonpreconditioned hearts and reversed cardioprotective effect of I-PC (LVDP $21 \pm 6 \%, \mathrm{P}<0.05$ vs. I-PC group, Table 2). 
Table 1. Preischemic values of the hemodynamic parameters in the non-preconditioned and preconditioned hearts. Effects of mito $\mathrm{K}_{\mathrm{ATP}}$ channels modulations and NAC in isolated rat hearts.

\begin{tabular}{|c|c|c|c|c|c|c|c|}
\hline Group & $\mathbf{n}$ & $\begin{array}{c}\text { CF } \\
\mathrm{ml} / \mathrm{min}\end{array}$ & $\begin{array}{l}\text { LVDP } \\
\text { mmHg }\end{array}$ & $\begin{array}{c}\text { LVEDP } \\
\text { mmHg }\end{array}$ & $\begin{array}{l}+\mathbf{d P} / \mathbf{d t}_{\max } \\
\quad \mathbf{m m H g} / \mathbf{s}\end{array}$ & $\begin{array}{l}-\mathbf{d P} / \mathbf{d t}_{\max } \\
\quad \mathbf{m m H g} / \mathbf{s}\end{array}$ & $\begin{array}{c}\text { HR } \\
\text { beats/s }\end{array}$ \\
\hline$T I$ & 16 & $13 \pm 1$ & $94 \pm 3$ & $6 \pm 1$ & $2641 \pm 185$ & $1947 \pm 177$ & $254 \pm 7$ \\
\hline$I-P C+I$ & 15 & $14 \pm 1$ & $93 \pm 2$ & $6 \pm 1$ & $2878 \pm 285$ & $1836 \pm 212$ & $272 \pm 5$ \\
\hline$D Z X+I$ & 15 & $15 \pm 1$ & $98 \pm 1$ & $6 \pm 1$ & $2607 \pm 221$ & $1877 \pm 139$ & $260 \pm 7$ \\
\hline$N A C+I$ & 13 & $12 \pm 1$ & $75 \pm 6$ & $5 \pm 1$ & $2019 \pm 201$ & $1529 \pm 111$ & $261 \pm 10$ \\
\hline $5-H D+I$ & 14 & $13 \pm 2$ & $78 \pm 6$ & $4 \pm 1$ & $2908 \pm 251$ & $1750 \pm 150$ & $250 \pm 7$ \\
\hline$I-P C+5-H D+I$ & 20 & $13 \pm 1$ & $81 \pm 2$ & $5 \pm 1$ & $2456 \pm 221$ & $1690 \pm 203$ & $253 \pm 4$ \\
\hline
\end{tabular}

Data are means \pm S.E.M., $\mathrm{n}=13-20$ in each group. CF - coronary flow $(\mathrm{ml} / \mathrm{min})$, LVDP - left ventricular developed pressure ( $L V$ systolic minus $\mathrm{LV}$ diastolic pressure, $\mathrm{mm} \mathrm{Hg}$ ), $+\mathrm{dP} / \mathrm{dt}_{\max },-\mathrm{dP} / \mathrm{dt}_{\max }-$ maximum rates of pressure development and fall, respectively $(\mathrm{mm} \mathrm{Hg} / \mathrm{s})$, LVEDP - left ventricular end-diastolic pressure $(\mathrm{mm} \mathrm{Hg}), \mathrm{HR}$ - heart rate (beats/min).

Table 2. Postischemic recovery of LVDP after global ischemia/reperfusion: effects of I-PC, mito KATP channels modulations and NAC in isolated rat hearts.

\begin{tabular}{lcccccc}
\hline Group & TI & I-PC + I & DZX + I & NAC + I & 5-HD + I & $\begin{array}{c}\text { I-PC + } \\
\text { 5-HD + I }\end{array}$ \\
\hline$\%$ & & & & & \\
$n$ & $29 \pm 3$ & $68 \pm 5^{*}$ & $70 \pm 5^{*}$ & $50 \pm 6^{*}$ & $26 \pm 7$ & $21 \pm 6$ \\
& 8 & 6 & 7 & 6 & 8 & 6 \\
\hline
\end{tabular}

Data are means \pm S.E.M. expressed in $\%$ of preischemic values. $N=6-8$ in each group. $* \mathrm{P}<0.05$ vs. control ischemic group (TI).

\section{Evaluation of myocardial oxidative state}

The levels of TBARS at the end of ischemia were significantly higher in ischemic hearts than those detected in non-ischemic myocardium (50.9 \pm 6.4 and $37.8 \pm 2.3 \mathrm{nmol} / \mathrm{g}, \mathrm{P}<0.05)$. I-PC decreased the levels of TBARS during subsequent prolonged ischemia to their value in the non-ischemic hearts $(37.9 \pm 2.7 \mathrm{nmol} / \mathrm{g}$, Fig. 4A). A more pronounced effect of ischemia and I-PC on production of ROS was demonstrated by measurement of concentration of $\mathrm{CD}$. $\mathrm{CD}$ concentration in nonischemic controls $(103.8 \pm 13 \mathrm{nmol} / \mathrm{g})$ was increased by TI more than two-fold $(241.9 \pm 34.4 \mathrm{nmol} / \mathrm{g}, \mathrm{P}<0.05$ vs. baseline preischemic values) and this effect was reversed in the preconditioned hearts $(104.2 \pm 12.8 \mathrm{nmol} / \mathrm{g}, \mathrm{P}<0.05$ vs. non-preconditioned ischemic hearts, Fig. 4B). As expected, pretreatment with antioxidant NAC also significantly reduced ROS generation during $\mathrm{TI}$ and decreased $\mathrm{CD}$ concentration in the ischemic myocardium to $110.8 \pm 8.5 \mathrm{nmol} / \mathrm{g}(\mathrm{P}<0.05 \mathrm{vs}$. ischemic controls $)$.

On the other hand, I-PC itself tended to enhance ROS generation prior to TI (CD 137.4 $\pm 20.6 \mathrm{nmol} / \mathrm{g}$, Fig. 5). Similarly to I-PC, opening of mito $\mathrm{K}_{\mathrm{ATP}}$ channels with diazoxide led to an elevation in ROS production before TI (CD 148.9 $\pm 9.1 \mathrm{nmol} / \mathrm{g}, \quad \mathrm{P}<0.05$ vs. nonischemic controls), whereas administration of $\mathrm{K}_{\mathrm{ATP}}$ channels blocker 5-HD during preconditioning phase markedly suppressed production of ROS before subsequent prolonged ischemia (CD $85 \pm 5.3 \mathrm{nmol} / \mathrm{g}$, $\mathrm{P}<0.05$ vs. non-treated preconditioned hearts). This effect was comparable with the reduction of $\mathrm{CD}$ following application of NAC in combination with I-PC (Fig. 5).

\section{Discussion}

The main objective of this study was to demonstrate whether opening of mito $\mathrm{K}_{\mathrm{ATP}}$ channels, either endogenous or by exogenously administered mito $\mathrm{K}_{\mathrm{ATP}}$ opener diazoxide, is involved in production of ROS and in the antiarrhythmic effect of PC during sustained ischemic challenge.

The occurrence of arrhythmias and myocardial infarction might be the direct consequence of increased production of ROS during myocardial ischemia. Free radicals have been implicated in the mechanisms of reversible postischemic contractile dysfunction (myocardial stunning), cardiac cell death, 


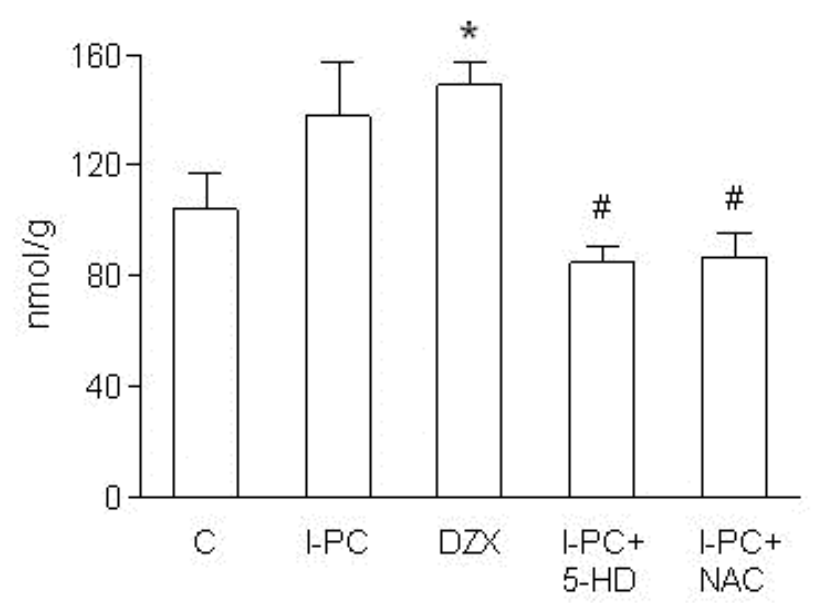

Fig. 5. Concentration of conjugated dienes in the rat myocardium before test ischemia: effects of I-PC, $K_{\text {ATP }}$ channels modulations and NAC. C- non-ischemic controls, I-PC- ischemic preconditioning alone, DZX - treatment with diazoxide alone, I-PC+5-HD- 5-hydroxydecanoate applied during ischemic preconditioning, I-PC+NAC - N-acetylcysteine applied during ischemic preconditioning. Values are means \pm S.E.M, $n=8-9$ in each group. ${ }^{*} \mathrm{P}<0.05$ vs. $\mathrm{C},{ }^{*} \mathrm{P}<0.05$ vs. I-PC.

electrophysiological derangements and they are also involved in the pathogenesis of chronic cardiovascular diseases (Kevin et al. 2005). Myocardial ischemiainduced arrhythmias may be mitigated by various antiradical interventions, such as inhibition of radical formation or by scavenging of free radicals (Bernier et al. 1989b, Tosaki et al. 1993, Sobey et al. 1993). In accordance, in the present study, 15-min pretreatment of the hearts with antioxidant NAC significantly decreased arrhythmias during subsequent ischemia (Figs 1 and 2) and improved postischemic recovery of contractile function (Table 2). In other studies, NAC administered throughout the experiment has also been shown to reduce myocardial stunning, however, it failed to limit infarct size in the in vivo canine model (Forman et al. 1988). In addition, in the study of Chen et al. (1995), postischemic functional recovery in NAC-treated hearts was not improved as compared with that in the untreated hearts indicating certain controversies in the results concerning the efficiency of antiradical treatment.

In our study, one cycle of I-PC did not change the temporal profile of arrhythmias, but significantly reduced the total number of VPB, number of episodes of VT, as well as the total duration of VT. Administration of diazoxide induced similar antiarrhythmic protection as classical I-PC (Fig. 2). One of the major determinants of arrhythmogenesis is the size of the occluded zone (Curtis 1998). Another factor that might influence the occurrence of arrhythmias is the changes in the heart rate (Bernier $e t$ al. 1989a). However, we can rule out both factors since similar technique of LAD coronary artery occlusion has been applied in all groups, and there were no differences in the size of ischemic area between the groups correlating with the reduction of coronary flow (Ravingerová et al. 1995), or in the heart rate. These results are in agreement with the data provided by Das and Sarkar (2005) and Végh and Parratt (2002), who demonstrated a reduction of arrhythmias in the preconditioned dogs and rabbits by a mechanism that involved opening of mito $\mathrm{K}_{\mathrm{ATP}}$ channels. Although electrophysiological mechanisms underlying antiarrhythmic protection conferred by one cycle of ischemic preconditioning have been shown to involve attenuation of spatial dispersion of repolarization between the epi- and endocardial layers of the myocardium as a substrate for reentry arrhythmias induced by ischemia (Botsford and Lukas 1998), the role of $\mathrm{K}_{\mathrm{ATP}}$ channels in antiarrhythmic effects is still a matter of debate. In the present study, the role of mito $\mathrm{K}_{\mathrm{ATP}}$ channels activation in the protection against ischemia-induced arrhythmias was further supported by the finding that application of their inhibitor 5-HD during the preconditioning phase partially abolished antiarrhythmic effect of I-PC and significantly increased the incidence of ventricular tachycardia (Fig. 3). Moreover, the role of mito $\mathrm{K}_{\mathrm{ATP}}$ channels opening in cardioprotective mechanisms was confirmed by the effects od I-PC and diazoxide on functional recovery upon ischemia/reperfusion and its reversal by 5 HD (Table 2). Our results are consistent with those of Munch-Ellingsen et al. (2000) or Végh and Parratt (2002) who found that 5-HD blunted cardioprotection in the preconditioned rats and dogs.

$\mathrm{K}_{\text {ATP }}$ channel activation may be related to a release of ROS during the preconditioning ischemia/reperfusion (Cohen et al. 2001). $\mathrm{O}_{2}^{-}$is a potent activator of myocardial mito $\mathrm{K}_{\mathrm{ATP}}$ channels. Therefore, ROS, such as $\mathrm{O}_{2}^{-}$generated during IPC, may activate mito $\mathrm{K}_{\mathrm{ATP}}$ channels by their direct action on the sulfhydryl groups of the channel protein leading subsequently to a cardioprotective effect due to $\mathrm{K}_{\mathrm{ATP}}$ opening (Zhang et al. 2001).

On the other hand, experimental evidence suggests that the opening of mito $\mathrm{K}_{\mathrm{ATP}}$ channels generates ROS and that these radicals represent a part of the cascade leading to cardioprotection (Pain et al. 2000, Forbes et al. 2001, Patel and Gross 2001). Cardioprotective effect of I-PC and diazoxide may be manifested during the phase of sustained ischemia by 
attenuation of ROS production and mobilization (activation) of antioxidant reserves (Maczewski et al. 2004, Glantz et al. 2005, Morihira et al. 2006), and in this respect, the role of mitochondria has been proposed. Moreover, pharmacological preconditioning by diazoxide has been found to be associated with an improved mitochondrial recovery after $\mathrm{I} / \mathrm{R}$ injury (Honda et al. 2005). We demonstrated by two methods suitable for detection of early and advanced changes in the oxidative state that enhanced ROS production in the ischemic myocardium was effectively suppressed in the preconditioned myocardium and hence, their proarrhythmic effects (Ravingerová et al. 1999) might be reduced as well. Measurement of conjugated dienes as primary products of lipid peroxidation was, however, more sensitive and using this method we were able to detect even less evident changes in oxidative state, such as those that occurred during early preconditioning ischemia/reperfusion and/or application of mito $\mathrm{K}_{\mathrm{ATP}}$ channels diazoxide. Our data show that both, I-PC and pretreatment with diazoxide caused an increase in ROS production (documented by an enhanced concentration of CD) prior to sustained ischemia, which was blocked by coadministration of 5-HD and/or NAC (Fig. 4). This is in agreement with the study of Obata and Yamanaka (2000) who demonstrated that the administration of $\mathrm{K}_{\mathrm{ATP}}$ channels openers cromakalim and nicorandil increased production of ROS that was blocked by 5-HD. Opening of the mito $\mathrm{K}_{\mathrm{ATP}}$ channel occurs upstream of the mitochondrial ROS generation in the protective pathway since this protection is abrogated by 2-mercaptopropionylglycine and NAC, a free radical scavenger (Tang and Tang 1991, Forbes et al. 2001, Zhang et al. 2001, Yue et al. 2002).

The role of $\mathrm{K}_{\mathrm{ATP}}$ channels activation as a final step in cardioprotective signaling mechanisms has been supported by the findings that activated protein kinase $\mathrm{C}$ (PKC) phosphorylates sarcolemmal $\mathrm{K}_{\mathrm{ATP}}$ channels (Hu et al. 1996), and that NO, PKC and MAPK-mediated mechanisms facilitate the opening of $\mathrm{K}_{\mathrm{ATP}}$ channels localized in mitochondria as well (Sato et al. 1998, Murphy 2004). Pain et al. (2000) demonstrated that diazoxide is protective even if it is only present before, rather than during, the sustained period of ischemia, suggesting that diazoxide acts as a trigger of preconditioning. It is possible that opening of a $\mathrm{K}_{\text {ATP }}$ channels may be involved as both a trigger and a mediator of preconditioning (Fryer et al. 2000). Exact mechanism by which opening of mito $\mathrm{K}_{\mathrm{ATP}}$ results in cardioprotection is not completely elucidated so far, although depolarization of the mitochondrial inner membrane and dissipation of membrane potential, in conjunction with limitation of calcium uptake by mitochondria (Holmuhamedov et al. 1999), regulation of mitochondrial volume and rate of respiration (Lim et al. 2002), as well as modulation of ROS production (Pain et al. 2000) could underlie protective effects. Another potential mechanism of attenuation of cell death by mito $\mathrm{K}_{\mathrm{ATP}}$ openers is related to the regulation of mitochondrial antiapoptotic proteins (bcl-2) involved in the limitation of the mitochondrial permeability and release of apoptosisinducing cytochrome c (Shimizu et al. 1999).

However, further studies are required to get more insight into the mechanisms by which mito $\mathrm{K}_{\mathrm{ATP}}$ channels activation might modify electrophysiological processes underlying antiarhythmic protection afforded by $\mathrm{PC}$ in the rat heart.

\section{Conclusions}

Our results indicate that pharmacological preconditioning of the heart by pretreatment with a selective mito $\mathrm{K}_{\mathrm{ATP}}$ channel opener diazoxide confers an effective protection against severe ischemia-induced ventricular arrhythmias (comparable with the effect of classical I-PC) and subsequently attenuates postischemic contractile dysfunction in the rat heart. Both forms of preconditioning were associated with a temporal moderate increase in generation of ROS prior to TI, and this effect was blocked by both, $\mathrm{K}_{\mathrm{ATP}}$ channel blockade and antiradical intervention and was followed by an attenuated ROS production at the end of sustained ischemia. Potential mechanisms of antiarrhythmic protection induced by PC might be related to the changes in the pro/antioxidant state of the myocardium and attenuation of their deleterious effects on the myocardium.

\section{Conflict of Interest}

There is no conflict of interest.

\section{Acknowledgements}

The authors are thankful to Mrs. I. Blažíčková and I. Formánková for their excellent technical assistance. This study was supported by grants VEGA SR 2/0173/08, 1/3442/06 and APVT 51-027404. 


\section{References}

ASEMU G, PAPOUŠEK F, OŠŤÁDAL B, KOLÁ̌̌ F: Adaptation to high altitude hypoxia protects the rat heart against ischemia-induced arrhythmias. Involvement of mitochondrial $\mathrm{K}_{\mathrm{ATP}}$ channel. J Mol Cell Cardiol 31: 1821-1831, 1999.

BERNIER M, CURTIS MJ, HEARSE DJ: Ischemia-induced and reperfusion-induced arrhythmias: importance of heart rate. Am J Physiol 256: H21-H31, 1989a.

BERNIER M, MANNING AS, HEARSE DJ: Reperfusion arrhythmias: dose-related protection by anti-free radicals interventions. Am J Physiol 256: H1344-H1352, 1989 b.

BOTSFORD MW, LUKAS A: Ishemic preconditioning and arrhythmogenesis in the rabbit heart: effects on epicardium vs. endocardium. J Mol Cell Cardiol 30: 1723-1735, 1998.

BRIL A: Cellular mechanisms of cardiac arrhythmias in the ischaemic and reperfused heart. EXS 76: 135-153, 1996.

CHEN W, GABEL S, STEENBERGEN CH, MURPHY E: A redox-base mechanism for cardioprotection induced by ischemic preconditioning in perfused rat heart. Circ Res 77: 424-429, 1995.

COHEN MV, YANG X-M, LIU GS, HEUSCH G, DOWNEY JM: Acetylcholine, bradykinin, opioids, and phenylephrine, but not adenosine, trigger preconditioning by generating free radicals and opening mitochondrial $\mathrm{K}_{\mathrm{ATP}}$ channels. Circ Res 89: 273-278, 2001.

CURTIS MJ: Characterisation, utilisation and clinical relevance of isolated perfused heart models of ischemia-induced ventricular fibrillation. Cardiovasc Res 39: 194-215, 1998.

DAS DK, MAULIK A: Preconditioning potentiates redox signaling and converts death signal into survival signal. Arch Biochem Biophys 420: 305-311, 2003.

DAS B, SARKAR CH: Is the sarcolemmal or mitochondrial $\mathrm{K}_{\mathrm{ATP}}$ channel activation important in the antiarrhythmic and cardioprotective effects during acute ischaemia/reperfusion in the intact anesthetized rabbit model? Life Sci 77: 1226-1248, 2005.

DHALLA NS, ELMOSELHI AB, HATA T, MAKINO N: Status of myocardial antioxidants in ischemia-reperfusion injury. Cardiovasc Res 47: 446-456, 2000.

DOWNEY J, OMAR B, OOIWA H, MCCORD J: Superoxide dismutase therapy for myocardial ischemia. Free Radic Res Commun 12: 703-720, 1991.

FORBES RA, STEENBERGEN CH, MURPHY E: Diazoxide-induced cardioprotection requires signaling through a redox-sensitive mechanism. Circ Res 88: 802-809, 2001.

FORMAN MB, PUETT DW, CATES CU, MCCROSKEY DE, BECKMAN JK, GRENE HL, VIRMANI R: Glutathione redox pathway and reperfusion injury: effect of $\mathrm{N}$-acetylcysteine on infarct size and ventricular function. Circulation 78: 202-213, 1988.

FRYER RM, EELLS JT, HSU AK, HENRY MM, GROSS GJ: Ischemic preconditioning in rats: role of mitochondrial $\mathrm{K}_{\mathrm{ATP}}$ channel in preservation of mitochondrial function. Am J Physiol 278: H305-H312, 2000.

GARLID KD, DOS SANTOS P, XIE Z-J, COSTA ADT, PAUCEK P: Mitochondrial potassium transport: the role of the mitochondrial ATP-sensitive K channels in cardiac function and cardioprotection. Biochim Biophys Acta 1606: 1-21, 2003.

GLANTZ L, AVRAMOVICH A, TREMBOVLER V, GURVITZ V, KOHEN R, EIDELMAN LA, SHOHAMI E: Ischemic preconditioning increases antioxidants in the brain and peripheral organ after cerebral ischemia. Exp Neurol 192: 117-124, 2005.

GROSS GJ, AUCHAMPACH JA: Blockade of ATP-sensitive potassium channel prevents myocardial preconditioning in dogs. Circ Res 70: 223-233, 1992.

GROSS G, FRYER RM: Sarcolemmal versus mitochondrial ATP-sensitive $\mathrm{K}^{+}$channels and myocardial preconditioning in dogs. Circ Res 9: 973-979, 1999.

GROVER GJ, D’ALONZO AJ, SLEPH PG, DZWONCZYK S, HESS T, DARBENZIO RB: The cardioprotective and electrophysiological effects of cromakalim are attenuated by meclofenamate through a cyclooxygenaseindependent mechanism. J Pharmacol Exp Ther 269: 536-540, 1994.

HAMADA K, YAMAZAKI J, NAGAO T: Shortening of action potential duration is not prerequisite for cardiac protection by ischemic preconditioning or a $\mathrm{K}_{\mathrm{ATP}}$ channel opener. J Mol Cell Cardiol 30: 1369-1379, 1998. 
HOLMUHAMEDOV EL, WANG L, TERZIC A: ATP-sensitive $\mathrm{K}^{+}$channel openers prevent $\mathrm{Ca}^{2+}$ overload in rat cardiac mitochondria. J Physiol Lond 519: 347-360, 1999.

HONDA HM, KORGE P, WEISS JN: Mitochondria and ischemia/reperfusion injury. Ann NY Acad Sci 1047: 248-258, 2005.

HU K, DUAN D, LI GR, NATTEL S: Protein kinase C activates ATP-sensitive $\mathrm{K}^{+}$current in human and rabbit ventricular myocytes. Circ Res 78: 492-498, 1996.

KEVIN LG, NOVALIJA E, STOWE DF: Reactive oxygen species as mediators of cardiac injury and protection: the relevance to anesthesia practice. Anesth Analg 101: 1275-87, 2005.

KLONER RA, PRZYKLENK K, WHITTAKER P: Deleterious effects of oxygen radicals in ischemia/reperfusion. Resolved and unresolved issues. Circulation 80: 1115-1127, 1989.

KOGURE K, WATSON BD, BUSTO R, ABE K: Potentiation of lipid peroxides by ischemia in rat brain. Neurochem Res 7: 437-454, 1982.

LIM KH, JAVADOV SA, DAS M, CLARKE SJ, SULEIMAN MS, HALESTRAP AP: The effects of ischaemic preconditioning, diazoxide and 5-hydroxydecanoate on rat heart mitochondrial volume and respiration. J Physiol Lond 545: 961-974, 2002.

MACZEWSKI M, DUDA M, PAWLAK W, RERESEWICZ A: Endothelial protection from reperfusion injury by ischemic preconditioning and diazoxide involves a SOD-like anti- $\mathrm{O}_{2}^{-}$mechanism. $J$ Physiol Pharmacol 55: 537-550, 2004.

MCCORD JM: Oxygen-derived free radicals in postischemic tissue injury. $N$ Engl J Med 312: 159-163, 1985.

MORIHIRA M, HASEBE N, BALJINNYAM E, SUMITOMO K, MATSUSAKA T, IZAWA K, FUJINO T, FUKUZAWA J, KIKUCHI K: Ischemic preconditioning enhances scavenging activity of reactive oxygen species and diminishes transmural difference of infarct size. Am J Physiol 290: H577-H583, 2006.

MUNCH-ELLINGSEN J, LOKEBO JE, BUGGE E, JONASSEN AK, RAVINGEROVÁ T, YTREHUS K: 5-HD abolishes ischemic preconditioning independently of monophasic action potential duration in the heart. Basic Res Cardiol 95: 228-234, 2000.

MURPHY E: Primary and secondary signaling pathways in early preconditioning that converge on the mitochondria to produce cardioprotection. Circ Res 94: 7-16, 2004.

MURRY CE, JENNINGS RB, REIMER KA: Preconditioning with ischemia: a delay of lethal cell injury in ischemic myocardium. Circulation 74: 1124-1136, 1986.

OBATA T, YAMANAKA Y: Block of cardiac ATP-sensitive $\mathrm{K}^{+}$channels reduces hydroxyl radicals in the rat myocardium. Arch Biochem Biophys 378: 195-200, 2000.

OHKAWA H, OHISHI N, YAGI K: Assay for lipid peroxides in animal tissues by thiobarbituric acid reaction. Anal Biochem 95: 351-358, 1979.

PAIN T, YANG XM, CRITZ SD, YUE Y, NAKANO A, LIU GS, HEUSCH G, COHEN MV, DOWNEY JM: Opening of mitochondrial $\mathrm{K}_{\mathrm{ATP}}$ channels triggers the preconditioned state by generating free radicals. Circ Res 87: 460466, 2000.

PATEL HH, GROSS GJ: Diazoxide induced cardioprotection: what comes first, $\mathrm{K}_{\mathrm{ATP}}$ channels or reactive oxygen species? Cardiovasc Res 51: 633-636, 2001.

QIU Y, GALINANES M, FERRARI R, CARGNONI A, EZRIN A, HEARSE DJ: PEG-SOD improves postischemic functional recovery and antioxidant status in blood-perfused rabbit hearts. Am J Physiol 263: H1243-H1249, 1992.

RAVINGEROVÁ T, TRIBULOVÁ N, SLEZÁK J, CURTIS MJ: Brief, intermediate and prolonged ischemia in the isolated crystalloid perfused rat heart: relationship between susceptibility to arrhythmias and degree of ultrastructural injury. J Mol Cell Cardiol 27: 1937-1951, 1995.

RAVINGEROVÁ T, LOKEBO JE, SUNDSET R, YTREHUS K: Preconditioning against contractile dysfunction in guinea pig papillary muscle depends on the opening of $\mathrm{K}_{\mathrm{ATP}}$-sensitive channels. Exp Clin Cardiol 3: 184-188, 1998.

RAVINGEROVÁ T, SLEZÁK J, TRIBULOVÁ J, DŽURBA A, UHRÍK B, ZIEGELHÖFFER A: Reactive oxygen species contribute to high incidence of reperfusion-induced arrhythmias in isolated rat heart. Life Sci 65: 19271930, 1999. 
RAVINGEROVÁ T, PANCZA D, ZIEGELHÖFFER A, STYK J: Preconditioning modulates susceptibility to ischemia-induced arrhythmias in the rat heart: the role of $\alpha$-adrenergic stimulation and $\mathrm{K}_{\mathrm{ATP}}$ channels. Physiol Res 51: 109-119, 2002.

SATO T, O'ROURKE B, MARBAN E: Modulation of mitochondrial ATP-dependent $\mathrm{K}^{+}$channels by protein kinase $\mathrm{C}$. Circ Res 83: 110-114, 1998.

SATO T, SASAKI N, SEHARASEYON J, O'ROURKE B, MARBAN E: Selective pharmacological agents implicate mitochondrial but not sarcolemmal $\mathrm{K}_{\mathrm{ATP}}$ channels in ischemic cardioprotection. Circulation 101: 2418-2423, 2000.

SHIMIZU S, NARITA M, TSUJIMOTO Y: Bcl-2 family proteins regulate the release of apoptogenic cytochrome $\mathrm{c}$ by the mitochondrial channel VDAC. Nature 399: 483-487, 1999.

SOBEY CG, DALIPRAM RA, WOODMAN OL: Allopurinol and amlopidine improve coronary vasodilatation after myocardial ischemia and reperfusion in anesthetized dogs. Br J Pharmacol 108: 342-347, 1993.

TANG LD, TANG ZM: Protective effects of SH-compounds on ischemia reperfusion induced arrhythmias in the isolated rat heart. Yao Xиe Хие Bao 26: 91-95, 1991.

TOSAKI A, SZERDAHELYI P, DAS DK: Reperfusion-induced arrhythmias and myocardial ion shifts: a pharmacologic interaction between pinacidil and cicletanine in isolated rat hearts. Basic Res Cardiol 87: 366384, 1992.

TOSAKI A, DROY-LEFAIX MT, PALI T, DAS DK: Effects of SOD, catalase, and a novel antiarrhythmic drug, EGB 761, on reperfusion-induced arrhythmias in isolated rat hearts. Free Radic Biol Med 14: 361-370, 1993.

VÉGH A, PARRATT JR: The role of mitochondrial $\mathrm{K}_{\mathrm{ATP}}$ channels in antiarrhythmic effects of ischaemic preconditioning in dogs. Br J Pharmacol 137: 1107-1115, 2002.

WALKER MJ, CURTIS MJ, HEARSE DJ, CAMPBELL RW, JANSE MJ, YELLON DM, COBBE SM, COKER SJ, HARNESS JB, HARRON DW, HIGGINS AJ, JULIAN DG, LAB MJ, MANNING AS, NORTHOVER BJ, PARRATT JR, RIEMERSMA RA, RIVA E, RUSSELL DC, SHERIDAN DJ, WINSLOW E, WOODWARD B: The Lambeth Conventions: guidelines for the study of arrhythmias in ischaemia infarction, and reperfusion. Cardiovasc Res 22: 447-455, 1988.

YANG CS, TSAI PJ, CHOU ST, NIU YL, LAI JS, KUO JS: The roles of reactive oxygen species and endogenous opioid peptides in ischemia-induced arrhythmia of isolated rat hearts. Free Radic Biol Med 18: 593-598, 1995.

YUE Y, QIN Q, COHEN MV, DOWNEY JM, CRITZ SD: The relative order of $\mathrm{mK}_{\mathrm{ATP}}$ channels, free radicals and $\mathrm{p} 38$ MAPK in preconditioning's protective pathway in rat heart. Cardiovasc Res 55: 681-689, 2002.

ZHANG DX, CHEN YF, CAMPBELL WB, ZOU AP, GROSS GJ, LI PL: Characteristics and superoxide-induced activation of reconstituted myocardial ATP-sensitive potassium channels. Circ Res 89: 1177-1183, 2001. 